Supplementary Table 2: Hazard ratios (HR) and 95\% confidence intervals (CI) from the univariable analysis of categorical potential risk factors in relation to hypertension incidence by sex: Tehran Lipid and Glucose Study (1999_ 2018)

\begin{tabular}{lcccccc}
\hline & \multicolumn{2}{c}{ Men } & \multicolumn{2}{c}{ Women } & \multicolumn{2}{c}{ Total population } \\
\cline { 2 - 7 } & HR(95\% CI) & p-value & HR(95\% CI) & p-value & HR(95\% CI) & p-value \\
\cline { 2 - 7 } Sex, women (reference) & - & - & - & - & $1.15(1.06-1.26)$ & 0.001 \\
Age categories, years & & & & & & \\
$-\quad \mathbf{2 0 - 2 9}$ & Reference & & Reference & & Reference & $<0.001$ \\
$-\quad \mathbf{3 0 - 3 9}$ & $1.48(1.21-1.81)$ & $<0.001$ & $2.16(1.76-2.65)$ & $<0.001$ & $1.82(1.58-2.10)$ & $<0.001$ \\
$-\quad \mathbf{4 0 - 4 9}$ & $2.07(1.68-2.55)$ & $<0.001$ & $4.71(3.89-5.76)$ & $<0.001$ & $3.27(2.83-2.77)$ & $<0.001$ \\
$-\quad \mathbf{5 0 - 5 9}$ & $3.18(2.56-3.95)$ & $<0.001$ & $7.59(6.14-9.38)$ & $<0.001$ & $5.10(4.38-5.92)$ & $<0.001$
\end{tabular}

BMI categories, $\mathrm{kg} / \mathrm{m}^{2}$

$-\quad<25$

$-\quad 25-30$

$-\quad \geq 30$

Central obesity, yes

Blood pressure categories

- Optimum

- Normal

- High normal

Hypercholesterolemia, yes

Low HDL-C, yes

Hypertriglyceridemia, yes

\section{Marital status}

- Single

- Married
Reference

$1.56(1.36-1.79)$

$2.35(1.96-2.81)$

$1.92(1.68-2.19)$

Reference

2.43(2.09-2.83)

4.67(4.0-5.45)

1.48(1.30-1.67)

$1.05(0.92-1.20)$

1.36(1.19-1.54)

$<0.001$

Reference

1.79(1.49-2.16)

$<0.001$

$<0.001$
Reference

2.14(1.82-2.51)

$3.82(3.25-4.49)$

$2.80(2.48-3.16)$

Reference

3.33(2.90-3.82)

7.01(6.04-8.13)

$1.98(1.76-2.24)$

1.19(1.04-1.37)

2.35(2.09-2.64)

$<0.001$

$<0.001$

$<0.001$

$<0.001$

$<0.001$

Reference

$2.90(2.62-3.21)$

$<0.001$

$<0.001$

$<0.001$

0.04

$1.10(1.00-1.21)$

$<0.001$

Reference

Reference

$3.09(2.33-4.10)$

$<0.001$

2.11(1.81-2.46)

$<0.001$ 


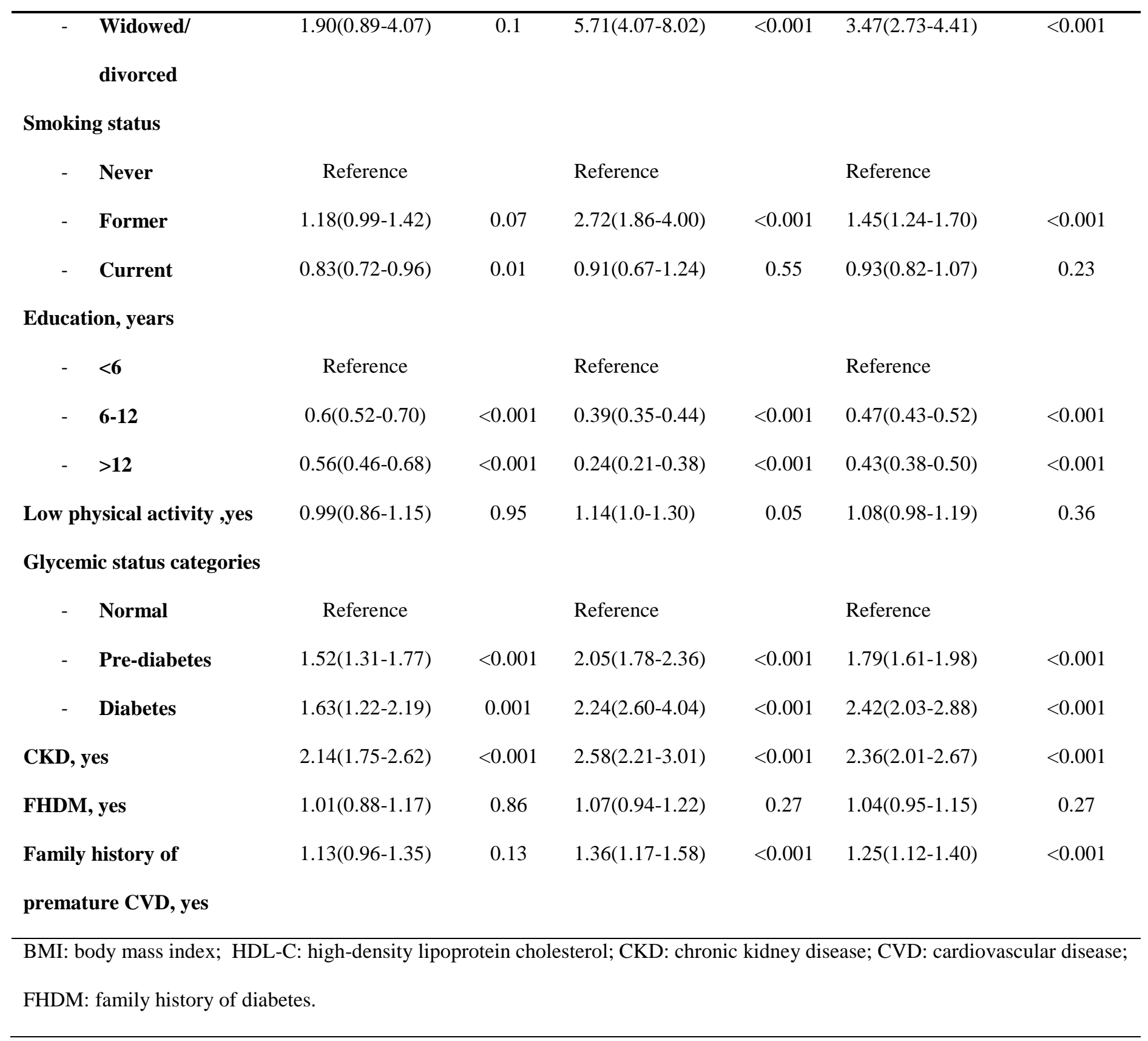

